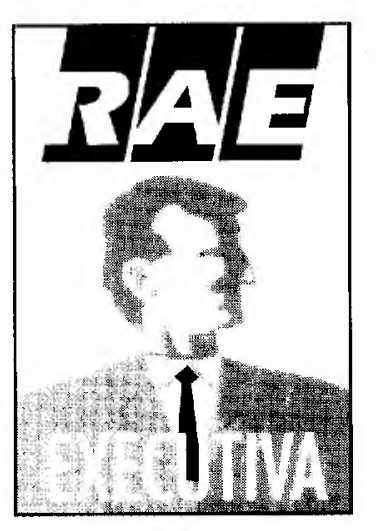

\title{
COMÉRCIO INTERNACIONAL E DESENVOLVIMENTO SUSTENTÁVEL: CONDICIONANTES PARA A AÇÃO EMPRESARIAL
}

Reflexão sobre os vínculos e controvérsias entre comércio internacional e a problemática ambiental.

Reflection on the links and controversies between the international trade and the environmental questions.

\section{PALAVRAS-CHAVE:}

Comércio internacional, meio ambiente, GATT, política comercial.

\section{KEY WORDS}

International trade, environment, GATT, trade policy.
*Economista Mestre em Administração Pública pela EAESP/ FGV Técnico de Desenvolvimento Administrativo da FUNDAP.
Uma característica básica das relações internacionais nos últimos anos consiste na preocupação com a dimensão ambiental do desenvolvimento econômico. $\mathrm{O}$ assunto está presente em inúmeras arenas, tais como os debates a respeito do controle do efeito estufa e da preservação da biodiversidade. Mais recentemente, verifica-se que o foco das atenções está privilegiando uma nova temática: as relações entre o comércio internacional e o meio ambiente.

A relevância que o tema está adquirindo deriva do papel central que as transações comerciais desempenham no cenário internacional, aliado ao fato de envolverem a intensa utilização dos recursos naturais. Em função da complexidade que permeia a matéria, os 
atores sociais estão empreendendo esforços no sentido de encontrar novas posturas que garantam tanto o incremento no comércio quanto a melhoria nas condições ambientais do planeta. As definições das estratégias que propiciem tais objetivos, porém, não são convergentes. Enquanto alguns advogam um processo mais gradual para a revisão da regulamentação que rege o sistema de comércio internacional, outros defendem quase que uma ruptura no padrão contemporâneo. $\mathrm{O}$ discernimento sobre a pertinência de cada um está longe da trivialidade. Cada lado dispõe de argumentos satisfatórios que devem ser levados em consideração por qualquer analista, de sorte que o confronto de idéias favoreça o melhor entendimento do fenômeno e o conseqüente posicionamento.

No contexto em particular, cabe ressaltar a opinião que a classe empresarial possui, tendo em vista, por um lado, a sua responsabilidade na produção e na comercialização de bens e serviços, e por outro, os impactos que sofrerão com as mudanças ora em curso.

Este trabalho pretende contribuir para a reflexão sobre os vínculos entre o comércio internacional e a problemática ambiental, salientando as principais controvérsias em pauta. Para tanto, abordam-se inicialmente as repercussões ambientais do livre comércio para depois se discutir o uso da política comercial com objetivos ambientais. Em seguida, são apresentados os desdobramentos para as empresas e as tendências do debate.Assim, espera-se identificar alguns contornos do cenário que, inexoravelmente, está sendo delineado para as relações comerciais internacionais.

A produção e a comercialização de bens trazem em seu bojo a utilização do estoque dos recursos naturais e a interferência nas condições normais dos ecossistemas. A opinião corrente acredita que o circuito produção-consumo acarreta prejuízos ecológicos em conseqüiência de diversos motivos: as tecnologias mais difundidas não são poupadoras de recursos, os interesses ambientais são secundários no processo decisório etc. A rigor, conquanto a história seja pródiga de exemplos que corroboram esse tipo de percepção, não é possível conceber que o comércio sempre leve a danos ao meio ambiente. $\mathrm{Na}$ atualidade, principalmente, quando os paradigmas convencionais de produção estão sendo superados, com a ampliação da responsabilidade empresarial para campos fora das fronteiras da firma, é mais factível aceitar a complementariedade das ações ambientais e comerciais. Caso contrário, restará tão-somente a proposição de restrições à circulação de mercadorias consideradas poluentes, seja em virtude de suas características intrínsecas, seja pelo processo produtivo utilizado em sua confecção. A adoção desse postulado não significa desconhecer as complexas tramas encontradas no desenvolvimento e que condicionam a sustentabilidade do mesmo. Significa, isso sim, o compromisso com o aprofundamento da compreensão dos fenômenos e a sugestão de novos caminhos.

Tendo em vista a questão do comércio internacional e o meio ambiente, o pontochave está no tratamento a ser dado às implicações das externalidades ambientais ${ }^{1}$, ou seja, como lidar com os custos ambientais gerados pelas transações de mercadorias de forma a não inviabilizar o livre comércio.

Para melhor compreender o assunto, é interessante utilizar uma tipologia com duas grandes categorias de externalidades ambientais: externalidades unidirecionais e externalidades mútuas ${ }^{2}$. As primeiras existem quando o exportador impõe custos ao país importador, enquanto as segundas contemplam a situação onde a poluição do país exportador compromete os recursos comuns da humanidade (a camada de ozônio, por exemplo).

As externalidades unidirecionais podem se dar tanto quando o bem é consumido pelo importador, quanto no próprio processo produtivo no interior do país exportador. No caso do consumo, um bom exemplo é quando o produto importado não consegue atender aos padrões ambientais domésticos. Assim ocorreu no litígio entre Alemanha e França a respeito da comercialização do creme de cassis. Para o governo alemão, o produto francês não obedecia aos níveis de conteúdo alcoólico estabelecidos por lei, devendo ser impedido de entrar no país. A argumentação, contudo, não foi considerada suficiente pela justiça para restringir o livre comér-
1. ARDA, M. Ecological-economic analysis for development policy: the context of internatjonal trade. São Paulo, mimeo, 1993, p. 4; SCHMIDHEINY, S. Mudando o rumo: uma perspectiva empresarial global sobre o desenvolvimento e meio ambiente. Rio de Janeiro: FGV, 1992, p. 16.

2. Para o aprofundamento do assunto, ver PEARCE, D., WARFORD, J. World without end: economics, environment and sustainable development. New York: 0xford University Press, 1993, p. 305-8. 
cio. Decisão antípoda foi manifestada na querela envolvendo a Dinamarca, quando esta proibiu a entrada de garrafas não-retornáveis; aqui, as cortes viram justificativas razoáveis para o estabelecimento de barreiras comerciais. Para ilustrar o caso das externalidades geradas a partir do processo produtivo, podese citar a produção florestal com tecnologias não-sustentáveis. Se os paí-

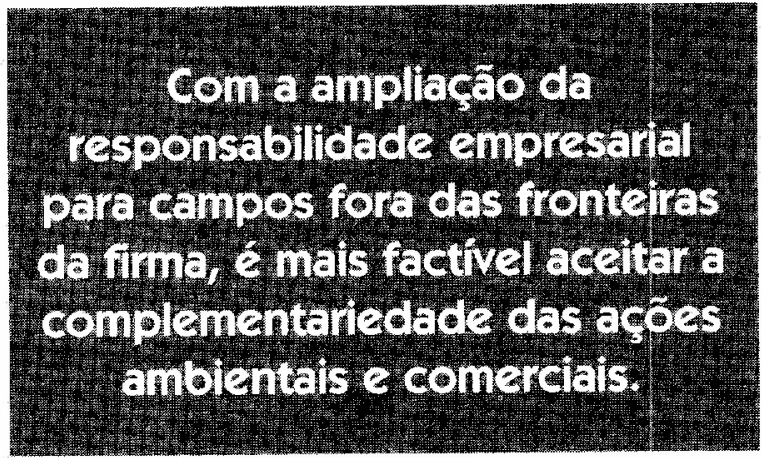
ses possuírem aqüúferos em comum, o importador poderá argüir que o desmatamento acelerado estará favorecendo os processos erosivos, comprometendo as condições de vida da ictiofauna. Também se poderá sustentar que a redução da biodiversidade trará prejuízos futuros para o país importador. Áustria e Holanda, por exemplo, já estão adotando restrições com esse teor.

A consideração das externalidades mútuas usualmente é feita sob os dispositivos de um tratado internacional, tal qual o Protocolo de Montreal e a Convenção da Basiléia, dado o comprometimento de recursos comuns. O instrumento básico é a sanção comercial aos não-integrantes e aos signatários faltosos. É interessante notar que o motivo para as restrições não são exclusivamente ambientais, mas também envolvem os problemas de concorrência entre países. Como a observância de padrões ambientais mais rigorosos implica uma elevação de custos, ao menos a curto prazo, aqueles que não se submeterem obterão uma vantagem comparativa. Para minimizar ou mesmo evitar os desvios, a ação conjunta das economias que se sentirem prejudicadas passa a ser uma estratégia com possibilidades de eficácia.

Todas essas conseqüências relacionadas às externalidades têm por origem os óbices que o mercado enfrenta para internalizar os custos ambientais. A gênese da questão pode residir tanto nas falhas de mercado quanto nos equívocos das políticas públicas, que distorcem a tomada de decisão dos agentes econômicos. Salientese que as dificuldades estão sendo enfrentadas em todas as partes do globo, uma vez que ainda é relativamente recente a inserção da dimensão ambiental nas arenas decisórias. O que é certo é que para os países subdesenvolvidos o assunto é de magnitude mais complexa, carecendo princi- palmente de estruturas de mercado mais competitivas, de informações de pesquisa e desenvolvimento - P\&D - e de práticas político-administrativas modernas.

A atenção que está sendo despertada pelo uso de dispositivos que tomam por base argumentos fundamentados em problemas de cunho ambiental e que visam a interferir nas trocas comerciais, decorre do incremento no chamado ecoprotecionismo. Esse fenômeno representa justamennão-tarifárias à entrada de produtos considerados danosos ao meio ambiente. Com isto, as economias prejudicadas estão questionando se as medidas implementadas não estão mais afetas à intenção de se as condições ambientais daqueles países.

$\mathrm{O}$ locus existente para diremir as pendências é o Acordo Geral de Comércio e Tarifas - GATT, instituído em 1947 com o objetivo de regulamentar o comércio internacional. Como na sua criação o meio ambiente não estava entre as preocupações centrais, não se encontram diretrizes específicas relacionadas ao assunto. A partir do vácuo, as discussões ainda são caracterizadas pela tentativa de interpretação das normas vigentes que poderiam apresentar rebatimentos na dimensão ambiental.

$\mathrm{O}$ esforço tem sido mais sistemático desde 1991, quando foi reativado o grupo de trabalho sobre comércio e meio ambiente, que nunca havia se reunido. A pauta então colocada pretendia:

" examinar como as disposições comerciais contidas nos atuais acordos internacionais te a instituição, notadamente pelos países desenvolvidos, de barreiras tarifárias e proteger os produtos internos e não tanto 
de meio ambiente se ajustam aos princípios do GATT;

avaliar a transparência e os efeitos comerciais das legislações ambientais nacionais; examinar os efeitos sobre o comércio das legislaçôes de embalagem e rotulagem que se destinam a proteger o meio ambiente."3

O resultado do trabalho, mesmo que tenha contribuido para a compreensão das indagações, não foi suficiente para gerar uma revisão do texto oficial. Isso só veio a ocorrer, de fato, neste ano de 1994, com a finalização da Rodada Uruguai do GATT. No interregno, a jurisprudência foi calcada em alguns poucos dispositivos já existentes.

Dentre as possíveis passagens para iluminar as controvérsias, o Artigo $X X$, que tratava das exceções gerais, precisa ser sublinhado. Nele estava posto que:

"Desde que essas medidas não sejam aplicadas de forma a constituir quer um meio de discriminação arbitrária, ou injustificada, entre os países onde existem as mesmas condições, quer uma restrição disfarçada ao comércio internacional, disposição alguma do presente capitulo será interpretada como impedindo a adoção ou aplicação, por qualquer parte contratante, das medidas:

b. necessárias à proteção da saude e da vida das pessons e dos animais è preservação dos vegetais;

g. relativas à conservação dos re-

cursos naturais esgotáveis, se tais medidas forem aplicadas conjuntamente com restrições à produção ou ao consumo nacionais"

Como o texto possuía ambigüidades $\mathrm{cm}$ sua redação, chegou a favorecer o uso de medidas protecionistas. Assim sucedeu na disputa entre os Estados Unidos e o México, quando o primeiro vetou a importação do atum mexicano, alegando que o método de pesca atentava contra a preservação dos golfinhos. A colocação não foi recepcionada pelo GATT, que assinalou que um país não tem competência para obrigar outro a adotar os padrões domésticos de controle.

Conforme alguns analistas, seria vital para o desembaraço das pendências que fosse esmiuçad o o significado dos conceitos empregados no Artigo $X X$, tais como "necessário", "injustificável" e "restrição disfarçada"s.

Um dos mecanismos criados para a resolução das divergências (ambientais e não-ambientais) foi o estabelecimento do Acordo sobre Barreiras Técnicas ao Comércio do GATT, ao término da Rodada Tóquio nos anos 70. No seu preâmbulo, o meio ambiente ganha destaque explícito, quando foi reconhecido que "a nenhum país deve ser proibido tomar medidas necessárias para assegurar a qualidade de suas exportações, ou para a proteção da vida on saúde humana, animal ou vegetal, para a proteção do meio ambiente (grifo nosso) ou para a prevenção de práticas que possam induzir a erros, desde que não sejan aplicadas de forma arbitrária ou injustificada entre os paises onde prevaleçam as mesmas condições, ou uma restrição disfarçada ao conércio internacional" Até o presente, no entanto, não houve contenciosos de natureza ambiental.

O túltimo segmento que contemplava os problemas ambientais estava inserido no Acordo sobre a Interpretação e Aplicação dos Artigos VI, XVI e XXIII do GATT. Em seu Artigo 11, que versava sobre subsídios que não estavam destinados à exportação, estabeleceu-se que os países seriam livres para recorrer aos subsídios enquanto instrumento de promoção de políticas econômicas e sociais. Seria possível, inclusive, "redistribuir geograficamente uma indústria para evitar congestionamento e problemas ambientais". 7 Posto nesses termos, depreende-se que, ao menos para o planejamento territorial, seria cabivel a implementação da política comercial com finalidades ambientais. No entanto, a redação do artigo era um pouco mais dúbia, dando margem às mais diversas opiniões. Por exemplo, se-
3. GAZETA Mercantil, 9 de outubro de 1991, p. 18.

4. ACORDO GERAL DE COMÉRCIO E TARIFAS, 1988

5. PROCÓPIO FILHO, A. (coord.) Ecoprotecionismo: comércio internacional, agricultura e meio ambiente. Brasília: IPEA, 1994, p. 47.

6. ACORDO GERAL... Op. cit.

7. Idem, ibidem. 
8. Esse segmento está baseado em PEREIRA, L. Comércio internacional e moio ambiente. Conjuntura Económica, v. $48, \mathrm{n}$. 4, p. 37-9, 1994.

9. Idem, ibidem, p. 37.

10. GAZETA MERCANTIL, 13 de abril de 1994, p. 1. ria correto considerar a falta de regulamentação ambiental como uma forma de subsídio? Certamente a falta de clareza não propiciaria o balizamento dos interessados.

Em função da inadequação cada vez mais acentuada das normas do GATT, aguardava-se algum tipo de alteração com a Rodada Uruguai. Sem embargo, o tema despertou atençôes especiais, motivando o posicionamento de dois grupos antagônicos: de um lado, os países desenvolvidos e as organizações ambientalistas, pressionando pela introdução de novas regras que flexibilizassem o uso de instrumentos da política comercial com objetivos ambientais; do outro, os países subdesenvolvidos - entre eles o Brasil - procurando minimizar as ligações entre comércio e meio ambiente. Ao término das negociações, em abril de 1994 , não se observou nenhuma modificação substancial, tendo-se impressão de que os contendores conseguiram um pequeno adiamento para as decisões definitivas.

Dessa vez, entretanto, foram postas algumas diretrizes que tocam no problema ${ }^{8}$. Em primeiro lugar, ficou explicitado que o crescimento do comércio mundial não pode ocorrer com a degradaçăo dos recursos naturais, comprometendo o sucesso do desenvolvimento sustentável. Em segundo lugar, o Código de Barreiras Técnicas ganhou nova redação, salientando que poderão existir normas com finalidades ambientais, com a ressalva de que não devem facilitar a discriminação no comércio. Por último, foi introduzida, no Código de Subsídios, uma categoria de subsídios nãoacionáveis, desde que visem a atividades de pesquisa, programas de desenvolvimento regional e adaptação de regulações ambientais.

Dentre as diretrizes, somente a terceira apresenta um potencial de impacto mais significativo. A primeira apenas reconhece um princípio para atuação, enquanto a segunda praticamente reproduz as condições anteriores. Já para os subsídios a situação é inovadora. Agora será possível incentivar as atividades que estejam operando há pelo menos dois anos a se adaptarem às novas regulamentaçōes, respeitando as seguintes restrições: "a. não podem ser recorrentes; $\boldsymbol{b}$. a assistência é limitada a $20 \%$ do custo de adaptação e não pode cobrir despesas de reposiçẫo e operacionais do novo investimento; c. devem ser proporcionats à redução planejada da melhoria ambiental; e $d$. devem ser disponiveis para todas as firmas que tenham que se adaptar às novas regulaçoes" $"$.

A medida mais concreta da Rodada Uruguai foi a criação de um subcomitê para discutir a relação entre meio ambiente e comércio, a ser presidido pelo embaixador brasileiro Luiz Felipe Lampréia. Com a iniciativa, a temática foi inserida de forma categórica nas agendas do Acordo e da futura Organização Mundial de Comércio - OMC, que sucederá o GATT a partir de 1995, não havendo mais como negar a premência da discussão. Não obs-
Ficou explicitado que o crescimanto do comércio nundial näo pode ocorrer com a

degradaçáo dos recursos

naturais, comprometendo 0

sucesso do desenvolvimento sustentável. tante essa relativa "vitória" dos defensores de um GATT mais ecológico, os divergentes se resguardaram através da imposição de um programa de trabalho que atendesse a seus interesses, afora $o$ aspecto do subcomitê ser temporário. Nos próximos dois anos, serão estudados os tópicos:

necessidade de novos dispositivos para tratar das questões ambientais; uso de legislação sobre embalagem e rotulagem (e.g., selo verde);

discriminação de produtos com base nos métodos e processos de produção; cooperação da OMC com outros organismos internacionais;

exportação de produtos perigosos ou proibidos internacionalmentc; transferência de recursos e tecnologias para mudanças no processo produtivo ${ }^{10}$.

A depender da dinâmica a ser instala$\mathrm{da}$, do avanço no conhecimento técnico e dos arranjos políticos, as regras no jogo 
internacional poderão ser substituídas. De antemão, sabe-se que o mote inicial não prevê a intromissão do GATT na conceituação do que é ambientalmente adequado ou não. Até quando a diretiva será preservada, porém, permanece uma incógnita.

Todas as transformações na matéria apresentada implicam, sem margem de dúvida, sensíveis mudanças na lógica de atuação das empresas. Algumas razões que corroboram a assertiva são bastante óbvias - legislação mais severa, produtos diferenciados etc. -, afinal o setor empresarial sempre desempenhou um papel central no sistema de trocas internacionais. Outras razões, por sua vez, estão mais atreladas a alguns condicionantes que ganham força neste fim de século. Mais explicitamente, o que se quer enfatizar é a nova tônica na relação empresa / cliente, onde a postura tradicional calcada exclusivamente na maximização dos benefícios do primeiro agente não é mais factível. Não é por menos que as modernas tecnologias administrativas estão por privilegiar a obtenção da qualidade na prestação de bens e serviços. Qualidade essa que inclui novos valores, como a preocupação ambiental.

Cabe notar que a realidade que está sendo sedimentada apresenta facetas que se mostram absolutamente favoráveis aos interesses empresariais. Se num primeiro momento as expectativas chegaram a alarmar segmentos do mundo dos negócios, face a um quadro de indefinições, o tempo demonstrou que o que estava por vir eram oportunidades para aqueles com espírito empreendedor. Novos mercados, estratégias de marketing revolucionárias, processos produtivos inovadores e ética empresarial são exemplos do temário agora predominante.

Do exposto não se deve concluir que o movimento de transformação se dá a custo zero. Este é significativo e poderá, incontestavelmente, excluir muitas firmas do mercado. O ponto fulcral é que o argumento não pode servir de desculpa para posturas conservadoras que ainda se ma- nifestam, que tendem a alegar a redução do lucro, como se houvesse um trade off entre lucratividade e responsabilidade ambiental ${ }^{11}$. Ora, os ciclos de inovação tecnológica são historicamente traumáticos pois requerem a superação dos paradigmas hegemônicos. E a redução do lucro será sentida justamente por aqueles que não se adaptarem às novas condições de concorrência, força motriz da economia de mercado. Essa é a visão destacada pelo trabalho desenvolvido pelo Business Council for Sustainable Development, que congrega empresários de diferentes origens, a respeito da sobrevivência das empresas sob as novas regras de competição:

"Um número cada vez maior de empresas de grande porte está adotando as estratégias de desenvolvimento sustentável e comprometendo-se com elas publicamente. Tais empresas estão ampliando seus conceitos entre os in teressados em suas operações, além dos empregados e dos acionistas, passando a considerar também os vizinhos, os grupos de interesse público (inclusive as organizações ambientais), os consumidores, os fornecedores, os governos e o público em geral. Elas estão se comunicando mais abertamente com esses novos interessados. Estão começando a entender que o grau de avaliação position ou negativa com que uma empresa é julgada, quanto à sua participação na resolução das questões de sustentabilidade, determinará, em larga medida, a sua viabilidade a longo prazo." 12

\section{A medida mais concreta da} Rodada Uruguai foi a criação de um subcomité para discutir a relação entre meio ambiente e comércio.
Valeria acrescentar que a competitividade internacional também seria fortalecida, lembrando que a globalização econômica está sendo acompanhada pelo reconhecimento generalizado do valor do meio ambiente $^{13}$. Isso tanto é verdadeiro que a influente International Standards Organization - ISO - também está preparando no-
11. Como exemplo, ver WALLEY, N., WHITEHEAD, B. It's not easy being green. Harvard Business Review, v. 72, n. 3, p. 46 52, 1994.

12. SCHMIDHEINY, S. Op. cit., p. 11.

13. N.R.: Ver artigo da seção RAEAmbiental. 
14. É importante reter que, ao contrário do muitas vezes difundido, näo existem indícios de que a não-adoção de uma regulamentação ambiental seja uma vantagem comparativa que induza à localização dos empreendimentos /World Bank, World development report 1992: development and the environment. Washington: The World Bank, 1992; CROPPER, M., OATES, W. Environmental economics: a survey. Journal of Economic Literature, v 30 , n. 2, p. 697-9, 1992).

15. VAUGHAN, S. Medio ambiente e comercio. Nuestro Planeta, tomo 5, n. 6, p. 11, 1993.

16. PROCÓPIO FILHO, A. Op. cit., p. 176 vos critérios para a mensuração da qualidade nos produtos, onde as variáveis ambientais ganharão destaque. Assim, tornase imprescindivel que empresas e governo atuem na definição de normas e padrões ambientais, bem como de procedimentos de fiscalização, que contribuam para as trocas internacionais e para o desenvolvimento sustentáve ${ }^{14}$.

Em meio ao turbilhão de opiniões divergentes, perspectivas distintas e indefiniçôes, um ponto pode ser considerado unânime: a imbricação das políticas de comércio internacionale de meio ambiente é inexorável. Qual o grau de racionalidade política, econômica e ambiental a ser atingido é outra questão. Caberá aos agentes sociais, nos âmbitos nacional e internacional, respondê-la através da capacidade de negociação. $E$ isso está longe de significar que o resultado scrá satisfatório para o comércio ou para o meio ambiente. Os processos recessivos que afligem boa parte da economia mundial poderão solapar os fluxos comerciais, recorrendo-se agora aos argumentos protecionistas calcados na questão ambiental. Por conseguinte, é primordial a instituição das arenas e das regras que irão reger os debates.

No caso do Acordo de Livre Comércio da América do Norte - NAFTA - já existem cláusulas específicas para a temática ambiental. Por exemplo, está posto que os padrốes de meio ambiente de um país não podem ser reduzidos sem justificativas e sem a consulta prévia aos demais signatários ${ }^{15}$.

O problema é que se requer um fórum ampliado que monopolize todas as áreas do sistema comercial internacional. Assim, talvez a transformação do GATT na OMC corresponda a um caminho que conduza a um porto seguro. Mesmo que alguns analistas possam levantar críticas ao desempenho histórico do Acordo, poucos não reconheceriam a sua efetiva participação para o dinamismo no comércio internacional após a Segunda Guerra Mundial. E existem indícios de que esse novo papel esteja sendo assumido. Como observava o ex-ministro Ricúpero antes do fe- chamento da Rodada Uruguai, "a 'convergência sistêmica' leva um número crescente de paises em desenvolvimento a aceitar, de bom ou mau grado, as normas e princípios enunciados apenas para os desenvolvidos. Em lugar de transferirem as negociaçöes para a OCDE, tem-se a sensação de que o GATT se transforma aos poucos em uma imensa OCDE um tanto diluida $a^{\prime \prime 6}$

A concretização da hipótese, entretanto, poderá trazer sérias repercussões aos países não-desenvolvidos, caso alguns cuidados não sejam observados. Basicamente, não podem ser esquecidos dois pontoschave: por um lado, é vital o fortalecimento do princípio da não-discriminação $\mathrm{co}^{-}$ mercial, base de sustentação do GATT; por outro, não pode ser renegado o fato de que os países apresentam condições de desenvolvimento e ecológicas distintas. Logo, qualquer iniciativa de uniformização de critérios deve ser combatida, garantindo o tratamento justo dos desiguais e preservando, inclusive, a eficiência no uso dos recursos.

Nesse sentido, também deve ser feita oposição à freqüente pretensão de homogeneizar as normas referentes aos métodos de produção. Os adeptos da idéia verbalizam a preocupação com a não-internalização dos custos ambientais em algumas economias, o que levaria a uma vantagem comparativa no comércio e à degradação ambiental. A colocação é louvável, mas a solução não está na imposição externa, pois esta desencadearia uma série de complicações nas relações internacionais. Melhor seria, isso sim, a cooperação internacional de forma a viabilizar a definição de preços reais, como, por exemplo, através da disseminação do princípio do usuário-pagador (e não apenas do poluidor-pagador), que, ao incidir sobre qualquer utilização dos recursos, possibilita o estabelecimento do valor econômico.

Por fim, vale lembrar que para o sucesso da internalização dos custos é necessária a obtenção de informações ainda não-disponívcis. Nessa empreitada, a universidade deverá colaborar com a introdução de novas tecnologias e com a realização de pesquisa básica, essa última há muito esquecida no Brasil. 